\title{
A clinical study of neurological soft signs in patients with schizophrenia
}

\author{
Mithun Dutta, Kamal Nath', Aparajeeta Baruah², Subrata Naskar ${ }^{1}$ \\ Department of Psychiatry, Pt. Jawaharlal Nehru Memorial Medical College, Raipur, Chhattisgarh, ${ }^{1}$ Department of Psychiatry, Silchar Medical \\ College and Hospital, Silchar, ${ }^{2}$ Department of Psychiatry, Lokopriya Gopinath Bordoloi Regional Institute of Mental Health, Tezpur, Assam, India
}

\begin{abstract}
Background and Aim: Neurological soft signs (NSSs) are "objectively measured, nonlocalizing abnormalities, not related to impairment of a specific brain region, reflecting improper cortical-subcortical and intercortical connections." The possibility of NSS as an endophenotype in schizophrenia has been studied across the globe. We aimed at finding the prevalence of NSS among patients with schizophrenia as well as the associations of NSS between various sociodemographic and illness variables. Subjects and Methods: One hundred patients between the age group of 16 and 60 years were serially selected from the inpatient department of a tertiary care hospital who have been diagnosed as a case of schizophrenia according to the International Classification of Diseases version 10 during 1 year period. A semi-structured pro forma was used to collect various demographic as well as illness data, and subjects were clinically evaluated for NSS using neurological evaluation scale. Results: The prevalence of NSSs was found to be $67 \%$, significant association was found between NSS and age, occupation, and duration of illness. A statistically significant correlation was found between NSS and age, NSS and duration of illness. Conclusion: The validity of NSS as an endophenotype lies in the fact that it should be independent of all sociodemographic and illness variables. However, our study evaluated some statistically significant findings between them. Hence, further researches are required with properly adjusted controls to find if the associations obtained between NSS and different variables here are true or whether there are some confounding factors included.
\end{abstract}

Key words: Demographics, endophenotype, neurological soft signs, schizophrenia

\section{Introduction}

As the field of psychiatry has been advancing gradually over the time, the concepts of the etiopathogenesis of the various psychiatric illnesses have also been evolving gradually. The advent of new age imaging techniques and other advanced investigation methodologies has helped the search for the ever alluring causes of the psychiatric illnesses beyond anything. However, the debate over the etiopathogenesis of schizophrenia, which has started from the Kreplinian age, is still continuing. Over the

Address for correspondence:

Dr. Subrata Naskar, Room No. 1, New PG Hostel, Silchar Medical College and Hospital, Silchar - 788 014, Assam, India.

E-mail: nsubrata.edu@gmail.com

\begin{tabular}{|l|l|}
\hline \multicolumn{2}{|c|}{ Access this article online } \\
\hline Quick Response Code: & Website: \\
\hline & www.ruralneuropractice.com \\
\cline { 2 - 3 } & \\
\hline
\end{tabular}

years, in the study of complex psychiatric diseases such as schizophrenia, concept of certain measurable components has come up, that is apparently invisible to the naked eyes but bridges the distal genotype and the disease, such as endophenotypes. Gottesman and Shields in $1973^{[1]}$ first adapted the term "endophenotype" and proposed four criteria to define it. Those being, "The endophenotype should be associated with illness in the population, should be heritable and primarily state-independent (manifests in an individual whether or not illness is active), and it should co-segregate with a psychiatric illness." Leboyer et al. in 1998 suggested additional criteria that endophenotypes should be found at a higher rate in the family members of the affected rather than those of unaffected..$^{[2]}$

This is an open access article distributed under the terms of the Creative Commons Attribution-NonCommercial-ShareAlike 3.0 License, which allows others to remix, tweak, and build upon the work non-commercially, as long as the author is credited and the new creations are licensed under the identical terms.

For reprints contact: reprints@medknow.com

How to cite this article: Dutta M, Nath K, Baruah A, Naskar S. A clinical study of neurological soft signs in patients with schizophrenia. J Neurosci Rural Pract 2016;7:393-9. 
Assessment of brain dysfunction in patients of schizophrenia took a new turn, when in 1988, Heinrichs and Buchanan ${ }^{[3]}$ reviewed the significance of neurological soft signs (NSSs) in the study of schizophrenia. NSS are "objectively measured, nonlocalizing abnormalities, not related to impairment of a specific brain region, reflecting improper cortical-subcortical and intercortical connections." ${ }^{[4]}$ Numerous scales have been developed such as the Heidelberger Scale, ${ }^{[5]}$ the Cambridge Neurological Inventory, ${ }^{[6]}$ and the Neurological Evaluation Scale (NES) ${ }^{[7]}$ to study brain dysfunction in schizophrenia through NSSs, as it is a much simpler, cost-effective way of assessing. Over the last few decades, numerous studies have been conducted to see the prevalence of NSS in schizophrenia, and the most accepted range is $50-65 \% .{ }^{[3]}$

The possibility of NSS as an endophenotype in schizophrenia has been studied across the globe. A meta-analysis by Chan et al., ${ }^{[8]}$ in 2010, that included 33 relevant and independent studies from 1966 to January 2008, concluded that "the substantial difference between schizophrenia patients and controls suggests that NSS meet one essential criterion (association with illness) of an endophenotype for schizophrenia." Among the latest studies, one Polish study conducted in 2014 by Kaluzynska and Rabe-Jablonska ${ }^{[4]}$ also concluded that "NSS still represent only candidates for an endophenotype of schizophrenia," however, they recommended the need for further studies about the usefulness of NSS as an endophenotype of schizophrenia.

The validity of NSS as an endophenotype lies in the fact that it should be independent of all sociodemographic and illness variables. Here lies the importance of studies that are aimed at finding this association. Hence, with this aim in mind, we have conducted this particular study in the North-Eastern part of India which not only targets at finding this association, but also the prevalence, pattern, and the intensity of NSS among patients with schizophrenia.

\section{Subjects and Methods}

This cross-sectional study was conducted at Lokopriya Gopinath Bordoloi Regional Institute of Mental Health (LGBRIMH), Tezpur, Assam (a town in the North-Eastern part of India), within a period of 1 year (2009-2010) after getting clearance from the hospital's Ethics Committee. LGBRIMH is a tertiary care institute providing mental health facility to the whole of the North-East region of India. One hundred patients from both sexes serially admitted in the inpatient ward diagnosed as a case of schizophrenia, according to the International Classification of Diseases version 10 (ICD-10), during the 1 year study period with age between 16 and 60 years, were included in the study. The patients with neurological disorders such as seizure disorder, movement disorders, and cerebral palsy as evaluated by a detailed neurological examination, patients with recent or current medical illness that may impair central nervous system function, patients with any other psychiatric comorbidity, or those with a life time history of head injury associated with loss of consciousness, seizures, neurological deficits, or surgical intervention were excluded from the study.

\section{Tools}

i. A semi-structured pro forma was designed for the study to record information regarding sociodemographic data such as age, gender, education, marital status, occupation, and illness variables such as family history of schizophrenia, duration of illness, and handedness

ii. ICD-10: The tenth revision of the ICD by the World Health Organization, Geneva (1992), was used. Patients who were diagnosed with schizophrenia as per the criteria of this manual were recruited into the study

iii. NES: Subjects were evaluated for NSS using NES. ${ }^{[7]}$ This is a 30 -item scale with ratings from 0 (absent) - 2 (extreme) for each item. The intensity of soft neurological signs is operationalized based on the NES scores from 0 (zero) to 2 (two) where 0 - absent, 1 - present-mild intensity, and 2 - present-high intensity. It takes about $40 \mathrm{~min}$ to administer this scale.

The NSS total score (sum of scores on all items) and NSS component scores were calculated.

The four component scores include:

a. NSS motor co-ordination sub-score is the sum of:

- Tandem walk

- Rapid alternating movements

- Finger-thumb opposition

- Finger to nose test.

b. NSS sequential complex motor performance sub-score is the sum of:

- Fist-ring test

- Fist-edge-palm test

- Ozeretski test

- Rhythm tapping production test.

c. NSS sensory integration sub-score is the sum of:

- Audio-visual integration

- Stereognosis

- Graphesthesia

- Extinction

- Right-left confusion. 
d. Primitive reflex sub-score is the sum of all the primitive reflexes added together.

\section{Consent}

Informed consent was taken from the primary care giver and the patient.

\section{Procedure}

Patients admitted in the inpatient ward of LGBRIMH, Tezpur, who were diagnosed with schizophrenia, were assessed initially for the inclusion and exclusion criteria. With the criteria being fulfilled, the sociodemographic and clinical variables were collected in the pro forma and the NES ${ }^{[7]}$ was administered.

\section{Statistical analysis}

The observed findings were tabulated properly and analyzed by relevant standard statistical tests using SPSS version 22 manufactured by IBM, Armonk, New York. compatible with windows operating system. Descriptive statistics in terms of percentage was used for categorical variables. Chi-square test was used wherever applicable. Pearson's coefficient correlation was applied for examining the relationship between variables specified. The results were compared with the available world literature in this topic.

\section{Results}

We found that the maximum number of subjects are between 20 and 39 years of age $(69 \%)$ with a mean age of 32.02 years. Among the total study subjects, maximum were found to be male $(69 \%)$, unmarried $(61 \%)$, primary educated $(45 \%)$ and unemployed $(45 \%)$. Detailed sociodemographic data are shown in Table 1. The duration of illness in most of the study subjects was found to be between 1 and 9 years (56\%), $37 \%$ of subjects have a positive family history of schizophrenia, and majority of the subjects are right-handed, that is, $89 \%$ [Table 2]. NSSs were present in $67 \%$ of subjects, the details of NES scores are shown in Table 3.

The associations between NSS score and the sociodemographic variables are shown in Table 4 . We found a statistically significant association with the NSS score and age, with the frequency and intensity of NSS increasing across the age group $(P=0.009$; $\mathrm{df}=8)$. The number and intensity of NSS score was more in males than in females, but no statistically significant difference was found. No significant difference of NSS score was found between the married and unmarried group, and NSS score was more or less same across the educational status, with maximum being in the
Table 1: Distribution of sociodemographic data of study subjects

\begin{tabular}{|c|c|}
\hline & Number of subjects \\
\hline \multicolumn{2}{|l|}{ Age (in years) } \\
\hline$<20$ & 8 \\
\hline $20-29$ & 35 \\
\hline $30-39$ & 34 \\
\hline $40-49$ & 18 \\
\hline$>50$ & 5 \\
\hline \multicolumn{2}{|l|}{ Sex } \\
\hline Male & 69 \\
\hline female & 31 \\
\hline \multicolumn{2}{|l|}{ Marital status } \\
\hline Married & 39 \\
\hline Unmarried & 61 \\
\hline Widow/widower & 0 \\
\hline Separated/divorcee & 0 \\
\hline \multicolumn{2}{|l|}{ Educational status } \\
\hline Illiterate & 8 \\
\hline Primary & 45 \\
\hline High school & 21 \\
\hline Higher secondary & 13 \\
\hline Graduate and above & 13 \\
\hline \multicolumn{2}{|l|}{ Occupation } \\
\hline Unemployed & 45 \\
\hline Daily wage earner & 9 \\
\hline Cultivator & 8 \\
\hline Business & 7 \\
\hline Skilled worker & 4 \\
\hline Service holder & 5 \\
\hline Professional & 7 \\
\hline Homemaker & 15 \\
\hline
\end{tabular}

Table 2: Distribution of data on illness variables of study subjects

\begin{tabular}{lc}
\hline Variables & Number of subjects \\
\hline Duration of illness in years & 9 \\
$<1$ & 28 \\
$1-4$ & 28 \\
$5-9$ & 15 \\
$10-14$ & 20 \\
$>15$ & \\
Family history & 37 \\
Positive & 63 \\
Negative & \\
Handedness & 89 \\
Right & 7 \\
Left & 4 \\
Mixed & \\
\hline
\end{tabular}

illiterate group. The number and intensity of NSS was found to be more in the business category followed by the group formed by cultivator and daily wage earner. This difference was found to be statistically significant $(P=0.049)$. We have also found high NSS score in the subjects with positive family history. Again an increase in the total NSS score was also 
Table 3: Distribution of neurological soft sign scores among study subjects

\begin{tabular}{lccccc}
\hline Score & Total $(\boldsymbol{n})$ & $\begin{array}{c}\text { Minimum } \\
\text { score }\end{array}$ & $\begin{array}{c}\text { Maximum } \\
\text { score }\end{array}$ & $\begin{array}{c}\text { Mean } \\
\text { score }\end{array}$ & SD \\
\hline NSS & 100 & 4 & 39 & 16.56 & 7.86 \\
$\begin{array}{l}\text { NSS-motor } \\
\text { sequencing }\end{array}$ & 100 & 0 & 18 & 6.09 & 3.48 \\
$\begin{array}{l}\text { NSS-motor } \\
\text { coordination }\end{array}$ & 100 & 0 & 8 & 1.5 & 1.75 \\
$\begin{array}{l}\text { NSS-sensory } \\
\text { integration }\end{array}$ & 100 & 0 & 8 & 3.39 & 2.27 \\
$\begin{array}{l}\text { NSS-primitive } \\
\text { reflex }\end{array}$ & 100 & 0 & 6 & 0.51 & 1.08 \\
\hline
\end{tabular}

NSS: Neurological soft signs, SD: Standard deviation

observed with the increase in the duration of illness, with the maximum score being in subjects with illness duration of more than 15 years. The difference was found to be statistically significant. We also found that NSS score was high in the mixed handed group and was low and almost equal in the right- and lefthanded subjects. Again from Table 3, we observed that the mean score obtained in NES was $16.56 \pm 7.86$. Subjects scored highest in the NSS motor co-ordination component of the scale $(6.09 \pm 3.48)$, followed by NSS sensory integration $(3.39 \pm 2.27)$. Hence, to sum up the significant findings, the NSS score is positively correlated with the age, with the positive family history, and also with the duration of illness, which depicts that increased age and increased duration of illness are associated with high NSS score, i.e., severe NSS.

\section{Discussion}

In this hospital-based observational study, we set out to find out the prevalence of NSS in patients with schizophrenia along with that to evaluate any association between the various sociodemographic and illness variables and NSS. Exactly, 100 subjects who were serially admitted in the institution were included in this study fulfilling the inclusion and exclusion criteria and were assessed using the NES. ${ }^{[7]}$

Previously conducted multiple observational studies have repeatedly documented a higher prevalence of NSS among patients with schizophrenia compared to healthy normal controls. Majority of the studies have reported the prevalence of NSS in patients with schizophrenia to be $50-65 \%$. We found the prevalence of NSS to be $67 \%$. Similar to our study, in their review, Heinrichs and Buchanan ${ }^{[7]}$ have estimated the prevalence of NSS in schizophrenia to be between 50\% and $65 \%$, as compared with $5 \%$ in control group. Gupta et al. ${ }^{\left[{ }^{[9]}\right.}$ in their study to assess NSS and developmental reflexes in those who had never received neuroleptic
Table 4: Distribution of neurological soft sign scores and association of various sociodemographic and illness variables with neurological soft signs

\begin{tabular}{|c|c|c|c|c|c|}
\hline \multirow[t]{2}{*}{ Variables } & \multicolumn{3}{|c|}{ NSS score (\%) } & \multirow[t]{2}{*}{ df } & \multirow[t]{2}{*}{$P$} \\
\hline & 0 & 1 & 2 & & \\
\hline \multicolumn{6}{|l|}{ Age in years } \\
\hline$<20$ & 62.5 & 12.5 & 25 & 8 & 0.009 \\
\hline $20-29$ & 34.3 & 45.7 & 20.0 & & \\
\hline $30-39$ & 23.5 & 41.2 & 35.3 & & \\
\hline $40-49$ & 38.9 & 5.6 & 55.6 & & \\
\hline$>50$ & 20 & 0 & 80 & & \\
\hline \multicolumn{6}{|l|}{ Gender } \\
\hline Male & 27.5 & 34.8 & 37.7 & 2 & 0.222 \\
\hline Female & 45.2 & 25.8 & 29 & & \\
\hline \multicolumn{6}{|l|}{ Marital status } \\
\hline Married & 38.5 & 23.15 & 38.5 & 2 & 0.30 \\
\hline Unmarried & 29.5 & 37.7 & 32.8 & & \\
\hline \multicolumn{6}{|l|}{ Education } \\
\hline Illiterate & 25 & 25 & 50 & 8 & 0.231 \\
\hline Primary & 33.3 & 33.3 & 33.3 & & \\
\hline High school & 23.8 & 19 & 57.2 & & \\
\hline Higher secondary & 38.5 & 38.5 & 23.1 & & \\
\hline Graduate/above & 46.2 & 46.2 & 7.7 & & \\
\hline \multicolumn{6}{|l|}{ Occupation } \\
\hline Unemployed & 24.4 & 35.6 & 40 & 14 & 0.049 \\
\hline Daily wage earner & 33.3 & 11.1 & 55.6 & & \\
\hline Cultivator & 12.5 & 37.5 & 50 & & \\
\hline Business & 0 & 57.1 & 42.9 & & \\
\hline Professional & 85.7 & 14.3 & 0 & & \\
\hline Skilled worker & 50 & 50 & 0 & & \\
\hline Service holder & 40 & 40 & 20 & & \\
\hline Homemaker & 53.3 & 20 & 26.7 & & \\
\hline \multicolumn{6}{|l|}{ Family history } \\
\hline Positive & 21.6 & 32.4 & 45.9 & 2 & 0.115 \\
\hline Negative & 39.7 & 31.7 & 28.6 & & \\
\hline \multicolumn{6}{|l|}{ Duration of illness } \\
\hline$<1$ & 88.9 & 0 & 11.1 & 8 & 0.000 \\
\hline $1-4$ & 32.1 & 50 & 17.9 & & \\
\hline $5-9$ & 39.3 & 39.3 & 21.4 & & \\
\hline $10-14$ & 13.3 & 26.7 & 60 & & \\
\hline$>15$ & 15 & 15 & 70 & & \\
\hline \multicolumn{6}{|l|}{ Handedness } \\
\hline Right & 32.6 & 33.7 & 33.7 & 4 & 0.459 \\
\hline Left & 42.9 & 28.6 & 28.6 & & \\
\hline Mixed & 25 & 0 & 75 & & \\
\hline
\end{tabular}

NSS: Neurological soft signs

medication and those who were receiving neuroleptic medication found the NSS to be present in $42 \%$ of subjects. Mechri et al. ${ }^{[10]}$ conducted a study, aimed at determining the prevalence and scores of NSS in patients with schizophrenia and their nonaffected siblings. They reported a NSS prevalence of $96.9 \%$ in patients with schizophrenia in comparison with 35.5\% in their nonaffected siblings $(P<0.0001)$. However, one of the early studies done to determine the prevalence of NSS in schizophrenia, "The Scottish First Episode Schizophrenia Study," by the Scottish schizophrenia 
research group (1987), ${ }^{[11]}$ found the prevalence of NSS to be much less, merely $20 \%$.

\section{Sociodemographic variables and neurological soft sign scores}

The assessment of the sociodemographic factors is of utmost importance in the study of NSS in patients with schizophrenia. The validity of NSS as a trait feature is established only then, if their occurrence is independent of such variables.

\section{Age}

In our study, we have included patients between 16 and 60 years of age. Patients below 16 years of age were excluded as they are not admitted without proper legal guardian. Those who were above 60 years were also excluded to rule out any age-related cognitive decline which may interfere with the accuracy of the rating scales as well as the possibility of emergence of few soft signs due to age-related degenerative changes leading to subtle hypofrontality.

In our study, majority of the patients were in the age group of 20-40 years (69\%) [Table 1]. The reason for this might be the fact that the illness is more severe during this period, and the loss of productive years forces the family members to bring the patient to mental health care. The frequency and intensity of NSS were found to increase with increasing age, and the difference was found to be statistically significant $(P=0.009)$ [Table 4].

Similar to this finding, NSSs have been reported to be dependent on age in studies done by Lane et al. ${ }^{[12]}$ and Chen et al.; ${ }^{[13]}$ however, some other studies ${ }^{[7,14,15]}$ conducted across various places have not found any association between age and NSS.

\section{Gender}

Majority of our subjects in our study were males (69\%) and the female patients being only $31 \%$ [Table 1]. Various psychosocial factors including social stigma may be responsible for lesser number of female patients getting admitted in the institute. However, we found that although the NSS score was found to be more in males, no statistically significant difference was found between the two groups [Table 4].

Similarly, gender has consistently been shown not to introduce variance in the presence and severity of NSS, with most of the studies. ${ }^{[7,14,16,17]}$ Although Heinrichs and Buchanan ${ }^{[3]}$ in their review found increased NSSs in male patients with schizophrenia, NSS tended to increase over a period of 5 years during follow-up and this increase was predominantly in males. As described in a study by McNeil et al., ${ }^{[18]}$ this maybe because "males were more likely to have been subjected to maternal obstetric complications and were more likely to have a nonremitting course of illness."

\section{Marital status}

In our study, we found that the majority (61\%) of the subjects were unmarried, and the reason for this might be the fact that more than $70 \%$ of subjects in our study were $<40$ years of age and in many of these subjects, illness started in their second or third decade of life [Table 1]. The NSS score was found to be more or less equal in both the groups, and there was no statistically significant difference among the two groups [Table 4].

No study was found to include marital status as a demographic variable for NSS score, and therefore association with marital status could not be compared.

\section{Occupation}

We found that more than $40 \%$ of patients were unemployed, and almost equal number of subjects were present in other categories. Fifteen percent of the subjects were homemakers. Higher prevalence of unemployment in the study subjects can be explained by the fact that occurrence of schizophrenia in the adolescence causes a significant impairment to a person's ability to attain new skills for vocational achievement. Productivity decreases as the disease becomes chronic. In our study, association between NSS and occupational status was found to be statistically significant $(P=0.049)$. Maximum NSS score was seen in the business class followed by the cultivator group and the daily wage earner group [Table 4].

Similar to results obtained in our study, one study done by Johnstone et al.$^{[19]}$ found a positive association between NSS and lower socio-occupational outcome. Majority of the other studies ${ }^{[9,20,21]}$ have found no association between NSS and socio-economic status. A study conducted by Griffiths et al., ${ }^{[16]}$ however, reported an inverse correlation between NSS and social class.

\section{Association between neurological soft signs score and illness variables \\ Family history \\ Positive family history of schizophrenia was present in $40 \%$ of our study subjects. Although the NSS score was more in subjects with positive family history, the difference was not found to be statistically significant [Table 4].}

Similar to our study, three other studies done by Flyckt et al.; $;^{[2]}$ Madsen et al.; $;^{[23]}$ and Lawrie et al.; $;^{[24]}$ respectively, tried to assess whether family history of schizophrenia 
or genetic loading has any influence on neurological functions. However, they reported no association between the prevalence of NSS and family history.

There are, however, other studies which have shown an excess NSS (especially of integrative signs) in patients with a positive family history of schizophrenia, in comparison to those without such a history, as in studies done by Walker and Shaye, ${ }^{[25]}$ Griffiths et al., ${ }^{[16]}$ and also when compared to healthy relatives of patients with schizophrenia. ${ }^{[16,26]}$

\section{Duration of illness}

Regarding the duration of illness, in our study, around $60 \%$ of subjects were with a duration of illness of 1-10 years, and 20\% subjects had illness for more than 15 years [Table 2]. A highly statistically significant association was found between the NSS score and the duration of illness, with more NSS score in subjects with longer duration of illness [Table 4].

Similarly, in a study done by Lane et al., ${ }^{[12]}$ NSSs have been reported to be dependent on the duration of illness.

\section{Handedness}

In our study, almost $90 \%$ of the patients were right-handed, and the rest 10\% comprised left-handed and mixed-handed subjects [Table 2]. The NSS score was found to be more in mixed-handed subjects, but no statistically significant association was found [Table 4].

An excess of mixed-handedness in patients with psychosis, especially with schizophrenia has been reported in studies done by Cannon et al..$^{[27]}$ and Malesu et al..$^{[28]}$ A study of Browne et al..$^{[17]}$ evaluated the relationship of NSS and mixed-handedness and inferred that subjects with mixed handedness have poor motor coordination when compared with subjects whose handedness is lateralized.

\section{Conclusion}

Our study comprises 100 consecutive cases of schizophrenia admitted in the inpatient ward of LGBRIMH, Tezpur, as per the inclusion criteria. This study is the first of its kind in this region where we made an attempt to see the prevalence of NSSs in patients with schizophrenia and to find their association with sociodemographic and illness variables. Most of the subjects in our study were males (69\%) between the age group of 20 and 39 years, and majority were unmarried (61\%). Most of the subjects were primary school dropout (45\%), and only a few were graduate and above (13\%), with majority of them being unemployed (45\%). Most of the subjects had a negative family history (63\%) and were right-handed (89\%), with duration of illness between 1 and 10 years (56\%).

The prevalence of NSSs was found to be $67 \%$, which is almost similar to most of the national and international studies. A significant association was found between the presence of NSS and age, occupation, positive family history, and duration of illness, and out of this, a statistically significant correlation was found between NSS and age as well as the presence of NSS and duration of illness.

This study being a hospital-based study with small sample size has its limitations, as the results may not reflect the exact picture of 'NSS in schizophrenia' in the community. The subjects were not followed up to detect any changes in NSSs over time. This being a observational study and does not have a control group, hence further researches are required with properly adjusted controls to see if the associations obtained between NSS and different variables here are true or whether there are any confounding factors included.

\section{Financial support and sponsorship \\ Nil.}

\section{Conflicts of interest}

There are no conflicts of interest.

\section{References}

1. Gottesman II, Shields J. Genetic theorizing and schizophrenia. Br J Psychiatry 1973;122:15-30.

2. Leboyer M, Bellivier F, Nosten-Bertrand M, Jouvent R, Pauls D, Mallet J. Psychiatric genetics: Search for phenotypes. Trends Neurosci 1998;21:102-5.

3. Heinrichs DW, Buchanan RW. Significance and meaning of neurological signs in schizophrenia. Am J Psychiatry 1988;145:11-8.

4. Kaluzynska O, Rabe-Jablonska J. Neurological soft signs as a candidate for endophenotype of schizophrenia. Psychiatr Pol 2014;48:5-18.

5. Schröder J, Niethammer R, Geider FJ, Reitz C, Binkert M, Jauss M, et al. Neurological soft signs in schizophrenia. Schizophr Res 1991;6:25-30.

6. Chen EY, Shapleske J, Luque R, McKenna PJ, Hodges JR, Calloway SP, et al. The Cambridge neurological inventory: A clinical instrument for assessment of soft neurological signs in psychiatric patients. Psychiatry Res 1995;56:183-204.

7. Buchanan RW, Heinrichs DW. The neurological evaluation scale (NES): A structured instrument for the assessment of neurological signs in schizophrenia. Psychiatry Res 1989;27:335-50.

8. Chan RC, Xu T, Heinrichs RW, Yu Y, Wang Y. Neurological soft signs in schizophrenia: A meta-analysis. Schizophr Bull 2010;36:1089-104.

9. Gupta S, Andreasen NC, Arndt S, Flaum M, Schultz SK, Hubbard WC, et al. Neurological soft signs in neuroleptic-naive and neuroleptic-treated schizophrenic patients and in normal comparison subjects. Am J Psychiatry 1995;152:191-6.

10. Mechri A, Slama H, Bourdel MC, Chebel S, Mandhouj O, Krebs MO, et al. Neurological soft signs in schizophrenic patients and their nonaffected siblings. Encephale 2008;34:483-9.

11. The Scottish First Episode Schizophrenia Study. I. Patient identification 
and categorisation. The Scottish Schizophrenia Research Group. Br J Psychiatry 1987;150:331-3.

12. Lane A, Colgan K, Moynihan F, Burke T, Waddington JL, Larkin C, et al. Schizophrenia and neurological soft signs: Gender differences in clinical correlates and antecedent factors. Psychiatry Res 1996;64:105-14.

13. Chen EY, Kwok CL, Au JW, Chen RY, Lau BS. Progressive deterioration of soft neurological signs in chronic schizophrenic patients. Acta Psychiatr Scand 2000;102:342-9.

14. Bartkó G, Zádor G, Horváth S, Herczeg I. Neurological soft signs in chronic schizophrenic patients: Clinical correlates. Biol Psychiatry 1988;24:458-60.

15. Mohr F, Hubmann W, Albus M, Franz U, Hecht S, Scherer J, et al. Neurological soft signs and neuropsychological performance in patients with first episode schizophrenia. Psychiatry Res 2003;121:21-30.

16. Griffiths TD, Sigmundsson T, Takei N, Rowe D, Murray RM. Neurological abnormalities in familial and sporadic schizophrenia. Brain 1998;121(Pt 2):191-203

17. Browne S, Clarke M, Gervin M, Lane A, Waddington JL, Larkin C, et al. Determinants of neurological dysfunction in first episode schizophrenia. Psychol Med 2000;30:1433-41.

18. McNeil TF, Blennow G, Lundberg L. Congenital malformations and structural developmental anomalies in groups at high risk for psychosis. Am J Psychiatry 1992;149:57-61.

19. Johnstone EC, Macmillan JF, Frith CD, Benn DK, Crow TJ. Further investigation of the predictors of outcome following first schizophrenic episodes. Br J Psychiatry 1990;157:182-9.

20. Flashman LA, Flaum M, Gupta S, Andreasen NC. Soft signs and neuropsychological performance in schizophrenia. Am J Psychiatry 1996;153:526-32.
21. Sanders RD, Keshavan MS, Schooler NR. Neurological examination abnormalities in neuroleptic-naive patients with first-break schizophrenia: Preliminary results. Am J Psychiatry 1994;151:1231-3.

22. Flyckt L, Sydow O, Bjerkenstedt L, Edman G, Rydin E, Wiesel FA. Neurological signs and psychomotor performance in patients with schizophrenia, their relatives and healthy controls. Psychiatry Res 1999;86:113-29.

23. Madsen AL, Vorstrup S, Rubin P, Larsen JK, Hemmingsen R. Neurological abnormalities in schizophrenic patients: A prospective follow-up study 5 years after first admission. Acta Psychiatr Scand 1999;100:119-25.

24. Lawrie SM, Byrne M, Miller P, Hodges A, Clafferty RA, Cunningham Owens DG, et al. Neurodevelopmental indices and the development of psychotic symptoms in subjects at high risk of schizophrenia. Br J Psychiatry 2001;178:524-30.

25. Walker E, Shaye J. Familial schizophrenia. A predictor of neuromotor and attentional abnormalities in schizophrenia. Arch Gen Psychiatry 1982;39:1153-6.

26. Rochford JM, Detre T, Tucker GJ, Harrow M. Neuropsychological impairments in functional psychiatric diseases. Arch Gen Psychiatry 1970;22:114-9.

27. Cannon M, Jones P, Huttunen MO, Tanskanen A, Murray RM. Motor co-ordination deficits as predictors of schizophrenia among Finnish school children. Hum Psychopharmacol Clin Exp 1999;14:491-7. Available from: http://www.doi.wiley.com/10.1002/\%28SICI $\% 291099$ $-1077 \% 28199910 \% 2914 \% 3$ A7\%3C491\%3A\%3AAID-HUP134\%3E3.0. CO\%3B2-V. [Last cited on 2015 Dec 08].

28. Malesu RR, Cannon M, Jones PB, McKenzie K, Gilvarry K, Rifkin L, et al. Mixed-handedness in patients with functional psychosis. Br J Psychiatry 1996;168:234-6 